\title{
Stem cells in embryonic skin development
}

\author{
Maria F. Forni, Marina Trombetta-Lima, Mari C. Sogayar \\ NUCEL, University of São Paulo (USP), São Paulo (SP), Brazil \\ Chemistry Institute, Biochemistry Dept., University of São Paulo, Brazil
}

\begin{abstract}
The skin is a complex stratified organ which acts not only as a permeability barrier and defense against external agents, but also has essential thermoregulatory, sensory and metabolic functions. Due to its high versatility and activity, the skin undergoes continuous selfrenewal to repair damaged tissue and replace old cells. Consequently, the skin is a reservoir for adult stem cells of different embryonic origins. Skin stem cell populations reside in the adult hair follicle, sebaceous gland, dermis and epidermis. However, the origin of most of the stem cell populations found in the adult epidermis is still unknown. Far more unknown is the embryonic origin of other stem cells that populate the other layers of this tissue. In this review we attempt to clarify the emergence, structure, markers and embryonic development of diverse populations of stem cells from the epidermis, dermis and related appendages such as the sebaceous gland and hair follicle.
\end{abstract}

Key words: Skin development, Embryonic skin, Epidermis, Dermis, Sebaceous Gland, Hair follicle.

\section{INTRODUCTION}

The skin is the primary barrier which protects the body from dehydratation, mechanical trauma and microbial insults, consisting of an outer epidermis and appendages separated from the underlying dermis by a basement membrane (Koster and Roop, 2007).

As a complex organ, the skin is composed of several tissues and a variety of accessory structures. The primary function of human skin, as well as that of other terrestrial animals, is to prevent excessive loss of water through the body, serving as a permeability barrier. Moreover, the skin is the first organ of the body's defense mechanism against external agents, providing protection against mechanical, chemical, thermal, and sunlight injuries in addition to infection by microorganisms. It also displays thermoregulatory sensory and metabolic functions (Fuchs and Raghavan, 2002). To repair damaged tissue and replace old cells, the skin depends on stem cell populations residing in the adult hair follicle, sebaceous gland, dermis and epidermis for continuous self-renewal (Fuchs, 2007).

The skin may be divided into three layers. The outermost layer, called the epidermis, with thickness varying from 0.06 to $1 \mathrm{~mm}$, is a squamous stratified epithelium composed mainly of keratinocytes, in addition to attachments which are inserted into the dermis such as follicles, sweat and sebaceous glands. The dermis (1-2 mm deep), separated from the epidermis by an epidermal basement membrane and consisting of the extracellular matrix, is a support system in which there are nails, blood and lymph vessels and nerve endings. The hypodermis (1-2 mm) is composed of adipose tissue which is molded to muscles and bones underlying the skin (Koster and Roop, 2007).

The mammalian skin is one of the best-studied epithelial systems containing stem cells to date, however, the origin of most of the stem cell populations found in the adult epidermis is still largely unknown (Benitah and Frye, 2012). Far more unknown is the embryonic origin of other stem cells which populate the other layers of this tissue. In this review we attempt to clarify the emergence, structure, markers and embryonic development of diverse populations of stem cells not only from the epidermis, which has been explored in several high quality reviews (Benitah and Frye, 2012; Driskell et al., 2011; Fuchs, 2007; Watt and Jensen, 2009), but also from the dermis and epidermis-related appendages such as sebaceous glands and hair follicles.

\section{STRUCTURE AND MORPHOLOGY OF THE EPIDERMIS}

As a stratified epithelium, the interfollicular epidermis consists of several layers, each with its own characteristics. The cells from the basal layer display two main functions, adhesion of the epidermis to the underlying dermis through the basement membrane, and providing new cells to replace the ones shed from the cornified exterior of the tissue (Candi et al., 2005) (Dai and Segre, 2004). In order to accomplish these functions and maintain epidermal homeostasis, these cells must maintain a stringent balance between quiescence and proliferation (Simpson et al., 2011). The main structural proteins within the basal keratinocytes are keratins 5 and 14, which have long been known as hallmarks for cells displaying proliferative potential in this tissue (Fuchs and Green, 1980). After commitment to differentiation, certain basal keratinocytes (epidermal stem cells) migrate from the basal into the suprabasal layer, also known as the spinous layer. After reaching this layer, these cells progressively lose their proliferative potential and begin to synthesize a set of structural proteins and enzymes associated with the assembly of the cornified envelope, such as involucrin, envoplakin and periplakin (Candi et al., 2005). The specific and best known keratins present in this layer are keratins 1 and 10 (Fuchs and Green, 1980). In the next layer, the granular one, the keratohyalin granules, consisting of the

Abbreviations: 5-bromo-2'-deoxyuridine(BrDU) - 2',3'-Cyclic-nucleotide 3'-phosphodiesterase (CNPase) - Dermal-Epidermal Junction (DEJ) - Glial Fibrillary Acid protein (GFAP) - Follicular Dermal Papilla (FDP) - Dermal Sheath (DS) - Platelet-derived growth factor A (PDGF-A) - Sonic hedgehog (Shh) - Sebaceous Gland (SG)

Corresponding author: Professor Mari Cleide Sogayar (mcsoga@iq.usp.br). Chemistry Institute - University of São Paulo. Av. Prof. Lineu Prestes, 748, B9S, Room 964. ZIP code: 05508000. São Paulo/SP, Brazil 
filaggrin precursor profilaggrin, group keratin fillaments into tight bundles, inducing the collapse of the cell to a flattened shape (Candi et al., 2005). This protein is used as a scaffold in the next stratum, the cornified layer, for its full maturation through the deposit and cross-linking of proteins such as loricrin and periplakin, among several others, by enzymes of the transglutaminase family. After addition of a set of lipids, the final differentiated cells are known as corneocytes (Serre et al., 1991).

The main epidermal appendages in mammals are the sweat glands, sebaceous glands and hair follicles, discussed in more detail in other sections. The sweat gland will not be explored here, but has been explored in several reviews elsewhere (Lobitz and Dobson, 1961; Richert et al., 2000) Other cells such as melanocytes, Langerhans and Merkel cells are important components of the epidermis, but will not be discussed here due to space and scope limitation constraints.

\subsection{Epidermal specification and differentiation - the role of interfollicular epidermal stem cells}

Interfollicular epidermal stem cells rely on an underlying basement membrane enriched in extracellular matrix (ECM) proteins and growth factors. Basal cells attach to this structure through adhesion complexes such as the hemidesmosomes, which contain a core of $\alpha 6 \beta 4$ integrins and focal adhesions of $\alpha 3 \beta 1$ integrins. These proteins also play a role in growth control and migration (Fuchs, 2007). The $\alpha 6$ and $\beta 1$ integrins have been used as markers of epidermal stem cells (Kaur and Li, 2000), similarly to p63, a p53 homologue which is expressed throughout the basal layer of the epidermis (Pellegrini et al., 2001) and has a putative function in maintaining these cells in a slow cycling state. These stem cells are responsible for a rapidly dividing progeny referred to as transit amplifying, which undergo a limited number of divisions before withdrawing from the cell cycle, committing to terminal differentiation and migrating towards the surface of the skin, generating dead, flattened, differentiated keratinocytes (Fuchs and Raghavan, 2002). The filagrin and involucrin intermediate filaments, expressed during this process, are specific markers of epidermal differentiation (Fuchs and Raghavan, 2002). These cells were described in the epidermal basal layer by Jones et al. in 1995 (Fuchs and Raghavan, 2002); several enrichment protocols are available in the literature for the isolation of epidermal stem cells, based on $\beta 1$ integrin expression (Kaur and Li, 2000), $\alpha 6$ integrin and CD71 (Tani et al., 2000) or Hoechst 33342 exclusion, combined with cell size (Dunnwald et al., 2001) (Reviewed in (Watt and Jensen, 2009)). The epidermis includes several other niches and populations of stem cells associated with the hair follicles, which are described in detail in another section.

\subsection{Embryonic origins of the epidermis}

In the mouse, after gastrulation a single cell layer of ectoderm is formed at embryonic day 9.5 (E9.5). Mesenchymal cells from the underlying layer begin to transmit signals that induce the stratification of the ectodermis, which will then generate the epidermis and also contribute to commitment of the several appendages present in this tissue (Koster and Roop, 2007; Millar et al., 1999). In response, the basal layer of the stratifying epidermis produces the basement membrane (Mikkola, 2007).
During the initial steps of stratification, which extend up to E12.5 to E15.5 in the mouse, proliferation is almost completely confined to the basal layer. During this period, a transient protective layer of tightly connected squamous endodermislike cells (M'Boneko and Merker, 1988) called periderm covers the epidermis. The function of the periderm is still unclear, but it likely forms an early epidermal barrier to protect the developing skin from constant exposure to the amniotic fluid (Benitah and Frye, 2012). Once the stratification program is completed, the periderm is shed and the epidermis has fully stratified and differentiated (around E17.5) (M'Boneko and Merker, 1988). These events are summarized in Fig. 1.

\subsection{Signaling pathways of the developing epidermis}

After gastrulation, emergence of the neuroectoderm is a key event, since it will allow the development of the nervous system and the skin epithelium. Neural induction is reinforced by a positive balance between fibroblast growth factors (FGFs) and inhibition of bone morphogenetic proteins (BMPs) (Gaspard and Vanderhaeghen, 2010). In the opposite direction, the epidermal fate is driven by the expression of BMPs, with additional Wnt signaling (Wilson and Hemmati-Brivanlou, 1995).

Another important cell signaling component in the formation of the epidermis is the Notch signaling pathway (Kolev et al., 2008). The process of lineage commitment between hair follicles and epidermal interfollicular lineages is regulated by Notch 1 and 2, as shown by experiments in which these genes were deleted (Yamamoto et al., 2003).

\section{HAIR FOLLICLE STRUCTURE AND MORPHOLOGY}

The hair follicle structure, located above the skin surface, may be divided into two different parts, a permanent upper part which does not visibly cycle and a lower part which is continuously being renovated with every hair cycle (Schlake, 2007). Once a hair follicle is produced it may undergo many of these cycles, continually generating, growing, and losing the hair shaft. In mammals the hair growth cycle includes three stages: anagen (follicle generation and hair production), catagen (follicle regression), and telogen (resting phase) (Philpott and Paus, 1998).

In the mouse, one of the most studied models for mammalian skin, there are four different types of hair. The guard hair has low abundance (2-10\%); it is straight, very long and contains two columns of medulla cells. This is also the only type of hair with two sebaceous glands instead of one as the other types have (Jones et al., 1994). Awl and auchene hair together comprise around $28 \%$ of the hair follicles of the mouse, being characterized as significantly shorter than the guard hair, with two or more columns of medulla cells. Auchene differs from the awl hair by a single sharp bend. Zigzag hair $(\sim 70 \%)$, the fourth type, contains a single column of medulla cells, and owes its name to three to four sharp bends in alternating directions. These different types of hair are considerably interspersed across the entire body of the mouse (Panteleyev et al., 2001).

\subsection{Embryonic origins of the hair follicle}

Development of the hair follicle is intrinsically related to the stratification of the embryonic epidermis. This process occurs in three phases, which are known as hair placode 
formation, hair follicle organogenesis and cytodifferentiation, further subdivided into eight morphologically distinct stages (Schmidt-Ullrich and Paus, 2005; Stenn and Paus, 1999).

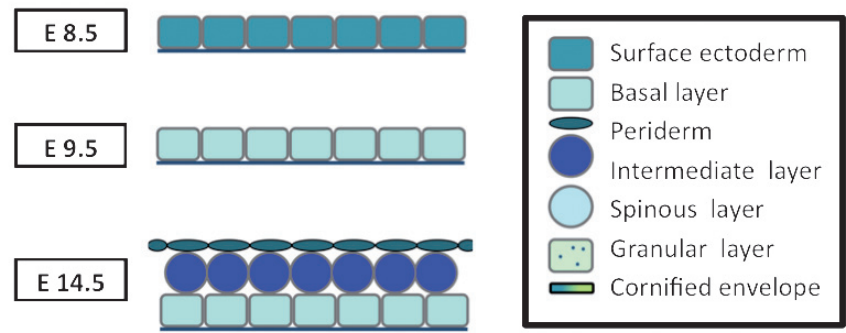

E 15.5
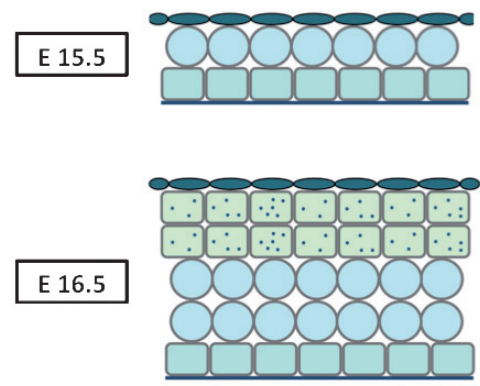

MARKERS

Loricrin

Filaggrin

E 18.5

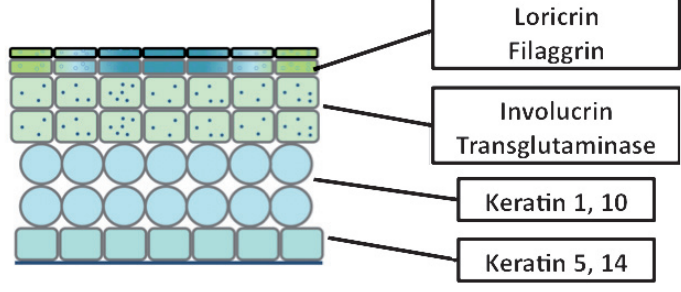

Figure 1: Timeline representing Epidermal Progenitor commitment steps during embryonic development
During the first stage, epidermal keratinocytes form clusters, which enlarge and elongate to generate hair placodes (E14). After this event, a cluster of specialized fibroblasts is formed just above the placode and the crosstalk of these two structures leads to increased proliferation of both (Michno et al., 2003). In the second stage, the enhanced proliferation leads to a downward growth of the epidermal component shaping the dermal papilla. The resulting structure, called the hair germ, is typically observed at E15.5. The keratinocytes continue to penetrate the forming dermis and envelop the dermal papilla, giving rise to the third-fifth stages, collectively known as the peg stage (E16.5-E17.5). The inner root sheath is then formed, triggering these cells to terminal differentiation, which generates the hair shaft (Stenn and Paus, 2001). Simultaneously, the outer root sheath starts to form a cylinder around the inner root sheath, and a bulbous peg structure is formed during stages 6-8 (E18.5).

The timelines described are for guard hairs, one of the most studied types of hair. Awl and Auchene hair follicles begin to form later on, at E15.5-E16, while zigzag hairs appear at E17 and do not reach the final process until postnatal life (Stenn and Paus, 1999). As illustrated in Fig. 2, the process of hair follicle formation is spatially and temporally controlled; the signals involved in this process are reviewed elsewhere (Andl et al., 2002; Benitah and Frye, 2012; Fuchs, 2007).

\subsection{Hair follicle-associated stem cell populations - markers, specification and differentiation}

\subsubsection{Bulge Stem Cells}

One reservoir of stem cells is the permanent lower part of the hair follicle, called the bulge. Bulge stem cells were originally identified as slow cycling cells through pulses of BrDU experiments, in what became popularly known as labelretaining cells (Bickenbach and Mackenzie, 1984; Braun et al.,
INDUCTION
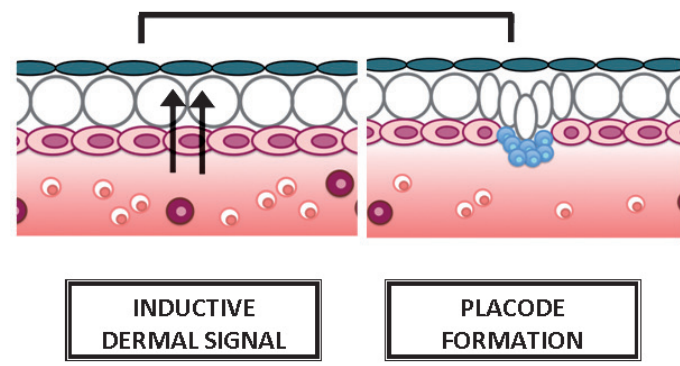

FORMATION

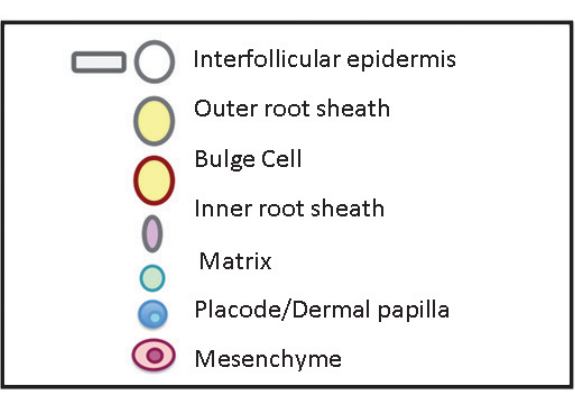

ORGANOGENESIS
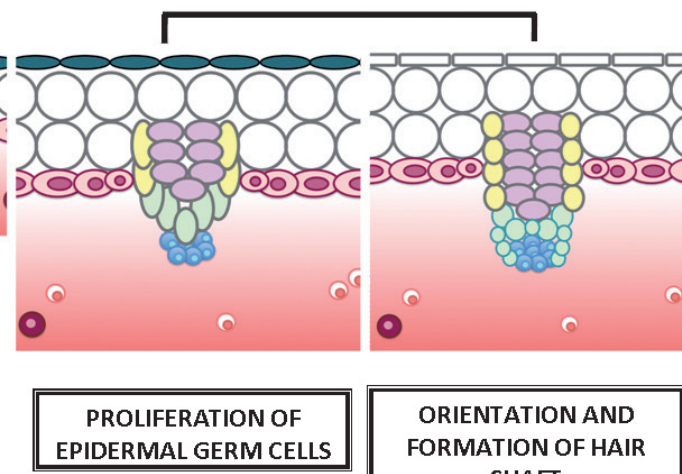

DERMAL PAPILLA

FORMATION
CYTODIFFERENTIATION

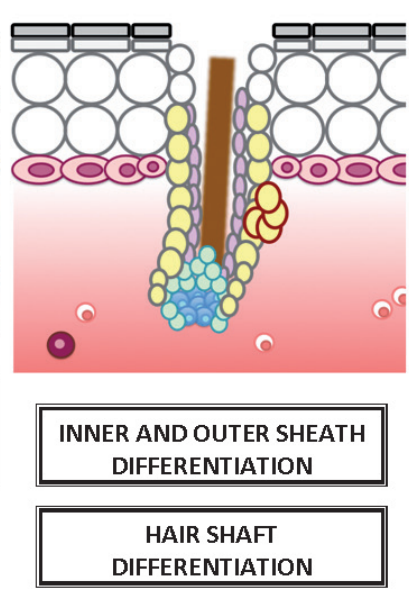

Figure 2: Embryonic developmental stages of the Hair Follicle. 
2003; Cotsarelis et al., 1990). More recently a large number of markers have been described for these cells, such as the high expression of $\alpha 6$ integrin (Li et al., 1998) and ABCG membrane transporter proteins (Tumbar et al., 2004), but all of these are shared with the interfollicular epidermal stem cells. One promising marker which appears to be specific for the bulge is the CD34 cell surface glycoprotein (Blanpain et al., 2004; Trempus et al., 2003). Lineage tracing analysis revealed the role of the bulge progeny: under normal homeostasis these stem cells contribute to all lineages of the hair follicle, with minimal contributions to the interfollicular epidermis and sebaceous glands (Kasper et al., 2011; Snippert et al., 2010). In more recent reports, the Lgr5 stem cell marker was considered to be a marker of bulge stem cells (Panteleyev et al., 2001) .

\subsubsection{Skps - skin precursors}

In 2001 Toma et al. described another multipotent precursor cell population in adult mammalian dermis, more specifically in the follicle dermal papillae (Toma et al., 2001). These cells -termed SKPs, for skin-derived precursors- were isolated and expanded from rodent and human skin and differentiated into both neural and mesodermal progeny, including cell types never found in skin, such as neurons. These cells expressed neuronal precursor markers such as Nestin and mesenchymal markers such as Vimentin, but not Fibronectin. Later on, the same group proposed that SKPs represent a multipotent neural-crest-like precursor which arises in embryonic mammalian tissues, and is maintained into adulthood (Fernandes et al., 2004). This may explain why SKPs are capable of differentiating into neurons ( $\beta$ III tubulin +$)$ and glial cells such as oligodendrocytes (CNPase + ) and astrocytes (GFAP+). In vivo, these cells were capable of generating myelinating Schwann cells, a fact of great impact in the spinal cord injury treatment area (Biernaskie et al., 2007).

\subsection{The mouse hair follicle junctional zone cells}

Recently it has been shown that cells of the junctional zone of the hair follicle, a region directly adjacent to the infundibulum and sebaceous gland, may contribute to the interfollicular and sebaceous lineages, presenting the Lrig1 protein as a specific marker (Jensen et al., 2009). Indeed, loss of Lrig1 leads to epidermal hyperplasia (Suzuki et al., 2002) in a mechanism most likely due to the lack of negative regulation by $c-m y c$ (Jensen et al., 2009). Therefore it appears that despite the fact that this population apparently does not contribute to the normal homeostasis of this tissue, these cells may act as stem cells in the case of injury.

\section{STRUCTURE AND MORPHOLOGY OF THE DERMIS}

The Dermal-Epidermal Junction (DEJ) is characterized by a basement membrane with components secreted by both basal keratinocytes and dermal fibroblasts. The DEJ acts not only by attaching the epidermis to the dermis, but also plays an important role in exchanging of signaling molecules between the two layers and allowing the transit of immune cells, and facilitates keratinocyte migration during wound-healing (Sorrell and Caplan, 2004). Almost imperceptible under regular staining, the DEJ undulating structure becomes clear with PAS or Giemsa staining. Its undulating feature is due to the presence of epithelial protuberances and dermal papillae (Prost-Squarcioni, 2006; Sorrell and Caplan, 2004).

DEJ has a complex and characteristic composition and may be subdivided into four regions by more detailed electron microscope analysis: (i) more superficially, the cell membrane of keratinocytes forming hemidesmosomes and melanocytes; followed by (ii) the lamina lucida, which is rich in pectin and laminin 5, 6 and 10; (iii) the osmiophilic lamina densa, composed mainly of type IV collagen and laminin 5 (electron dense); and more deeply (iv) the sub-basal lamina filamentous zone (Prost-Squarcioni et al., 2008; Sorrell and Caplan, 2004). Anchoring fibers are composed of collagen VII.

Located between the epidermis and hypodermis, the dermis is a connective tissue that acts supporting and protecting the epidermis. The dermal layer consists of fibroblasts, dendritic cells, macrophages/monocytes, neutrophils and lymphocytes, embedded in an extracellular matrix mainly composed of collagenous and elastic fibbers (Prost-Squarcioni, 2006; ProstSquarcioni et al., 2008; Sorrell and Caplan, 2004). The width of the dermis varies according to its anatomic location, being thicker on the back of the palms and soles, for instance (Sorrell and Caplan, 2004). The dermal layers may be subdivided into the more superficial papillary dermis and the reticular dermis. Separating these two layers is the subpapillar vascular plexus, and at the lower limit of the reticular dermis, the cutaneum vascular plexus separates the dermis from the hypodermis (reviewed in (Sorrell and Caplan, 2004), (Kanitakis, 2002)). The limits between the papillary dermis and the epidermis show an undulating pattern due to the presence of dermal papillae which contain tactile corpuscles and vascular components (Kanitakis, 2002). The papillary and reticular dermis differ greatly in their extracellular matrix composition and structure. The papillary dermis contains collagen fibers, composed mainly of collagen type II and III in disorganized loose bundles, and thin elastic fibers composed of elastin stretching perpendicular to the DEJ (reviewed in Sorrell and Caplan, 2004). The reticular dermis displays more compact collagen fibers which tend to be parallel to the skin surface and thicker elastic fibers (Kanitakis, 2002). The ground substance, composed of glycosaminoglycans and proteoglycans, rich in hyaluronic acid, fills the space between cells and fibers (Kanitakis, 2002; Prost-Squarcioni, 2006).

\subsection{Embryonic origins of the dermis}

The dermis has multiple embryonic origins (Driskell et al.). Fibroblasts are differentiated based on their position along three anatomical divisions: anterior-posterior, proximal-distal and dermal-nondermal (Rinn et al., 2006). Head and facial fibroblasts derive from the neural crest, while dorsal and ventral trunk fibroblasts derive from somitic and lateral plate dermomyotomes, respectively (Driskell et al.; Rinn et al., 2008). It has been shown that primary adult fibroblasts retain several features of the embryonic pattern of expression of HOX genes, homeodomain transcription factors which act to specify position identity during development, homeostasis and regeneration (Rinn et al., 2008).

Cells derived from the Follicular Dermal Papilla (FDP) and the Dermal Sheath (DS) differ from other dermal fibroblasts by their in vitro biological properties; support for epidermal cell growth, aggregative behavior in culture depending on Versican (Feng et al.) and upregulation of specific biomarkers 
(alkaline phosphatase, alpha smooth muscle actin, epimorphin and protease-activated receptor-1 (reviewed in (Ohyama et al., 2010)). After formation of the hair follicle precursor, the placode (E14.5), an aggregate of mesenchymal cells, the dermal condensate, is recruited below the placode at the base of the follicle (Driskell et al.; Ohyama et al.). Signaling between the condensate and the placode leads to the downward growth of the follicle into the dermis and encapsulation of the dermal condensate by epithelial cells, forming the mature FDP (Driskell et al.; Millar, 2002). The FDP cell number does not increase during follicular downward growth; its size is correlated with the hair fiber dimensions (Ohyama et al.). The mature FDP induces the surrounding epithelial matrix cells to proliferate, migrate and differentiate (Driskell et al.; Millar, 2002; Schneider et al., 2009).

\subsection{Dermis - niche and signaling pathways}

Platelet-derived growth factor A (PDGF-A) is expressed in developing hair follicle epithelium, and its receptor (PDGF$\mathrm{R} \alpha$ ) is expressed in the dermal condensate. Knockout mice for PDGF-A develop thinner dermis, misshapen hair follicles, smaller dermal papillae, abnormal dermal sheaths, thinner hair and reduced cell proliferation in the dermis and dermal sheaths compared to wild type mice, suggesting that PDGF-A plays a role in FDP, dermal sheath and dermal fibroblast establishment (Karlsson et al., 1999). Wnt signaling has a key role in recruitment of the dermal condensate, which is unable to develop in the absence of epithelial $\beta$-catenin, a downstream effector of the WNT signaling pathway (Schneider et al., 2009; Zhang et al., 2009). Sonic hedgehog (Shh) knockout mouse embryos show disrupted formation of the FDP (Karlsson et al., 1999). Shh signaling controls the expression of a subset of FDPspecific signature genes, being critical for subsequent signaling modulating proliferation and further downward growth of the follicular epithelium, in addition to development of the FDP (Schneider et al., 2009; Woo et al.). Wnt5a is expressed in the developing dermal condensate in wild type but not in Shhnull mice embryos, indicating that Wnt5a is a target of Shh in hair follicle morphogenesis (Reddy et al., 2001). Shh-null skin analysis showed that Shh is not a component of the first epithelial signal (Schneider et al., 2009). Dermal Smoothened (smo) loss of function results in loss of the dermal condensate and overexpression of Shh-dependent Noggin. This phenotype is partially rescued by the knockdown of noggin in the hair follicle by increasing the expression of epithelial shh (Woo et al.).

Laminin-511 mutants show developmental defects by E16.5, with decreased length and structure of primary cilia in vitro and in vivo. Inhibition of the laminin-511 receptor $\beta 1$ integrin disrupted FDP primary cilia formation and hair development. Laminin-511 triggers noggin expression through a mechanism that is dependent both on Shh and PDGF (Gao et al., 2008), showing the importance of laminin-511 for FDP maintenance.

The peribulbar DS, which covers the outside of the hair follicle, contains mesenchymal cells that contribute to the maintenance and regeneration of the FDP (Jahoda and Reynolds, 2001; Driskell et al., 2011). Upon amputation of the lower vibrissae follicle or surgical removal of the FDP alone in adult mice a new FDP was formed, suggesting that DS cells contribute to reconstitution of the new FDP (reviewed in (Ohyama et al., 2010)).
4.3 Specification and differentiation of the dermal papillae and its role in hair follicle development

The FDP gene expression pattern is heterogeneous and depends on the hair follicle type. It has been shown that Sox2 is expressed in all dermal papillae at E16.5, but from 18.5E onwards its expression is confined to the FDP of guard/awl/ auchene follicles, whereas CD133 is expressed in FDP associated with all hair follicle types (Driskell et al., 2009). Sox2 distinct subpopulations express different sets of genes in addition to the FDP gene signature (Driskell et al., 2009; Driskell et al.). FDP cells are not believed to divide, but during anagen the number of dermal cells in the dermal papillae increases, probably due to migration of cells from the DS (Chi et al.). Inhibition of $\beta$-catenin signaling in FDP cells resulted in reduced proliferation of epithelial cells inducing catagen and preventing anagen induction, possibly through inhibition of the FGF pathway (Driskell et al., 2011; Enshell-Seijffers et al., 2010). During anagen, FDP induces downward growth of the stem cells in the secondary hair germ. A quantitative analysis using the rodent vibrissa model indicated that the hair inductivity capacity of FDP cells is altered between early anagen and mid-anagen, being higher in the former, a phenomenon probably linked to the proliferative activity (Iida et al., 2007). Specific FDP markers which are upregulated during anagen in the adult mouse skin are the Corin serine protease and Sox-2 (Driskell et al., 2011), highlighting the crucial role of FDP signaling for hair follicle development. The FDP is also a reservoir of multipotent stem cells (Biernaskie et al., 2009; Hoogduijn et al., 2006; Lorenz et al., 2008; Wong et al.). At least three different subpopulations of progenitor cells may be identified: (i) Sox-2 positive cells, which are associated with Wnt, BMP, and FGF signaling; (ii) Sox-2 negative cells, associated with Shh, Insulin Growth Factor (IGF), Notch, and Integrin pathways; and (iii) skin-derived precursors (SKPs), which may differentiate into adipocytes, smooth myocytes and neurons in vitro; they are believed to originate from Sox-2 positive cells, and in part from the neural crest (Biernaskie et al., 2009; Lorenz et al., 2008; Wong et al.). The fact that cells isolated from different anatomical locations (including the back skin derived from the dermomyotome) display multipotent stem cell characteristics suggests that the hair follicle environment, rather than the embryonic origin, induces the generation of cells with the characteristics of neural crest derivatives (Driskell et al., 2011). A comparative analysis between the mesenchymal stem cells (MSCs) isolated from FDP and DS and those isolated from bone marrow showed that these MCs have similar morphology and population doubling time and express the same cell surface biomarkers (Hoogduijn et al., 2006). Also, both cell populations had the capacity to differentiate into the same mesenchymal lineages (osteoblasts, adipocytes, chondrocytes and myocytes) at similar rates and extent of differentiation (Hoogduijn et al., 2006). Progenitor cells derived from the FDP have also been explored as a source for generation of iPS cells (Tsai et al., 2010; Tsai et al., 2011). As a non-invasive source of progenitor cells, the dermal papilla and dermal sheath are viable and promising candidates for use in the clinic.

\section{STRUCTURE AND MORPHOLOGY OF THE SEBACEOUS GLAND}

Sebaceous glands are important in the maintenance of the hair, since absence of these glands was associated with scarring 

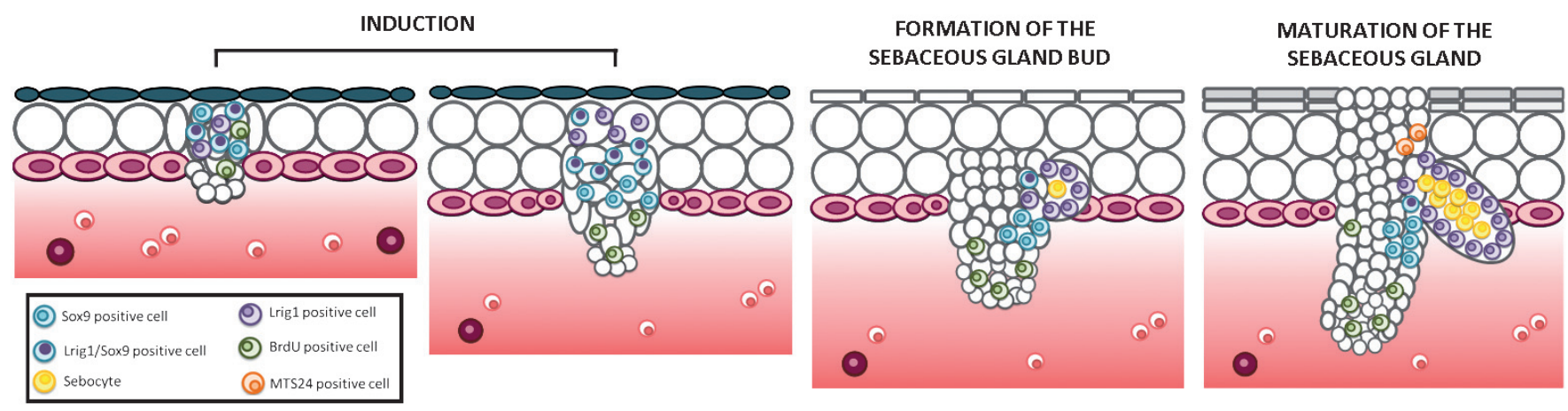

Figure 3: Stem cell involvement during Sebaceous Gland embryonic development

alopecia and doxorubicin-induced hair loss (Al-Zaid et al., 2011; Selleri et al., 2006). The sebaceous glands are composed mainly of sebocytes, which are highly specialized epithelial cells that release their sebum content through a process that culminates in the rupture of the cell membrane and cellular extravasation known as holocrine secretion (Frances and Niemann, 2012).

The majority of sebaceous glands are an integral part of a pilosebaceous unit, although this structure can appear as an independent structure in mutant mice lacking hair follicles (Mecklenburg et al., 2001; Nakamura et al., 2001; Schneider and Paus, 2010).

\subsection{Embryonic origins of the of the sebaceous gland}

The Sebaceous Gland (SG), of ectodermal origin, develops late in embryogenesis in the upper portion of the $\mathrm{HF}$, from the same lineage as that of keratinocytes. During the differentiation process Sox9 and Lrig1 are initially coexpressed by epidermal progenitor cells, but SG is driven by the asymmetric cell fate decision of Lrig1- positive stem cells but not of MTS24/Plet1-positive precursor cells (Frances and Niemann, 2012). Nevertheless, Sox-9 ablation in the embryo led to failed SG formation, even though Sox-9 is not expressed in the SG lineage or in its resident precursors (Nowak et al., 2008), indicating a more complex role for Sox-9 in SG morphogenesis. During homeostasis of adult mouse skin, Lrig1-positive cells contribute to the infundibulum and the sebaceous glands (Jensen et al., 2009), as illustrated in Fig. 3.

\subsection{Sebaceous gland stem cell -- niche and signaling pathways}

Blimp1, a transcriptional repressor, was shown to be a marker of the early stage SG-residing progenitor cell linage. Loss of Blimp1 leads to elevated c-myc expression, augmented cell proliferation and SG hyperplasia, resulting in enhanced bulge stem cell activity (Horsley et al., 2006), suggesting that Blimp1 is important for maintenance of SG progenitor cells. In addition, SG fails to develop in gamma-secretase null mice, in a mechanism dependent on Notch proteolysis (Pan et al., 2004). Inhibition of the Shh pathway selectively suppresses sebocyte development, whereas its activation leads to an increase in the size and number of SG (Allen et al., 2003). Knockout mice for CD109, a glycosylphosphatidylinositol glycoprotein which negatively regulates TGF- $\beta$ signaling, also display SB hyperplasia (Mii et al.). Activation of the Protein Kinase C system by phorbol 12-myristate 13-acetate (PMA) in immortalized sebocytes stimulated lipid synthesis (a marker of sebocyte differentiation) with translocation and downregulation of the cPKC $\alpha$ and nPKC al.). On the other hand, Wnt pathway inhibition appears to be crucial for SG development, since Smad7 transgenic induction perturbed hair follicle morphogenesis and differentiation and accelerated SG morphogenesis (Han et al., 2006). Smad7 binds to $\beta$-catenin, inducing its degradation and thereby inhibiting the Wnt/ $\beta$-catenin signaling pathway (Han et al., 2006). The Wnt pathway is also overexpressed in sebaceous gland carcinoma (Erovic et al.). Taken together, these findings show that SG development and maintenance involves a unique gene signature that interplays with the HF and FDP signaling pathways.

\section{CONCLUDING REMARKS}

The skin constitutes a reservoir for adult stem cells of different embryonic origins. Skin stem cell populations reside in the adult hair follicle, sebaceous gland, dermis and epidermis; however, the origin of most of these stem cell populations is still unknown. In this review we attempted to clarify the emergence, structure, markers and embryonic development of diverse populations of stem cells from the epidermis, dermis and related appendages such as the sebaceous gland and hair follicles. Further studies on skin stem cell specification and commitment are crucial for development of the knowledge of the dynamics of this tissue and for effective cell therapy protocols. 


\section{REFERENCES}

AL-ZAID T, S VANDERWEIL, A. ZEMBOWICZ AND S LYLE 2011. Sebaceous gland loss and inflammation in scarring alopecia: a potential role in pathogenesis. J Am Acad Dermatol. 65:597-603.

ALLEN M, M GRACHTCHOUK, H SHENG, V GRACHTCHOUK, A WANG, L WEI, J LIU, A RAMIREZ, D METZGER, P CHAMBON, J JORCANO AND AA DLUGOSZ 2003. Hedgehog signaling regulates sebaceous gland development. The American journal of pathology. 163:2173-2178.

ANDL T, ST REDDY, T GADDAPARA AND SE MILLAR 2002. WNT signals are required for the initiation of hair follicle development. Dev Cell. 2:643-653.

BENITAH SA AND M FRYE 2012. Stem cells in ectodermal development. J Mol Med (Berl). 90:783-790.

BICKENBACH JR AND IC MACKENZIE 1984. Identification and localization of label-retaining cells in hamster epithelia. J Invest Dermatol. 82:618-622.

BIERNASKIE J, M PARIS, O MOROZOVA, BM FAGAN, M MARRA, L PEVNY AND FD MILLER 2009. SKPs derive from hair follicle precursors and exhibit properties of adult dermal stem cells. Cell stem cell. 5:610-623.

BIERNASKIE J, JS SPARLING, J LIU, CP SHANNON, JR PLEMEL, Y XIE, FD MILLER AND W TETZLAFF 2007. Skin-derived precursors generate myelinating Schwann cells that promote remyelination and functional recovery after contusion spinal cord injury. J Neurosci. 27:9545-9559.

BLANPAIN C, WE LOWRY, A GEOGHEGAN, L POLAK AND E FUCHS 2004. Self-renewal, multipotency, and the existence of two cell populations within an epithelial stem cell niche. Cell. 118:635-648.

BRAUN KM, C NIEMANN, UB JENSEN, JP SUNDBERG, V SILVAVARGAS AND FM WATT 2003. Manipulation of stem cell proliferation and lineage commitment: visualisation of label-retaining cells in wholemounts of mouse epidermis. Development (Cambridge, England). 130:5241-5255.

CANDI E, R SCHMIDT AND G MELINO 2005. The cornified envelope: a model of cell death in the skin. Nat Rev Mol Cell Biol. 6:328-340.

CHI WY, D ENSHELL-SEIJFFERS AND BA MORGAN 2010. De novo production of dermal papilla cells during the anagen phase of the hair cycle. J Invest Dermatol. 130:2664-2666.

COTSARELIS G, TT SUN AND RM LAVKER 1990. Label-retaining cells reside in the bulge area of pilosebaceous unit: implications for follicular stem cells, hair cycle, and skin carcinogenesis. Cell. 61:1329-1337.

DAI X, AND JA SEGRE 2004. Transcriptional control of epidermal specification and differentiation. Curr Opin Genet Dev. 14:485-491.

DRISKELL RR, C CLAVEL, M RENDL AND FM WATT 2011. Hair follicle dermal papilla cells at a glance. J Cell Sci. 124:1179-1182.

DRISKELL RR, A GIANGRECO, KB JENSEN, KW MULDER AND FM WATT 2009. Sox2-positive dermal papilla cells specify hair follicle type in mammalian epidermis. Development (Cambridge, England). 136:2815-2823.

DRISKELL RR, VR JUNEJA, JT CONNELLY, K KRETZSCHMAR, DW TAN AND FM WATT 2012. Clonal growth of dermal papilla cells in hydrogels reveals intrinsic differences between Sox2-positive and -negative cells in vitro and in vivo. J Invest Dermatol. 132:1084-1093.

DUNNWALD M, A TOMANEK-CHALKLEY, D ALEXANDRUNAS, J FISHBAUGH AND JR BICKENBACH 2001. Isolating a pure population of epidermal stem cells for use in tissue engineering. Experimental dermatology. 10:45-54.

ENSHELL-SEIJFFERS D, C LINDON, M KASHIWAGI AND BA MORGAN 2010. beta-catenin activity in the dermal papilla regulates morphogenesis and regeneration of hair. Developmental cell. 18:633-642.

EROVIC BM, AAL HABEEB, L HARRIS, DP GOLDSTEIN, D KIM, D GHAZARIAN AND JC IRISH 2012. Identification of novel target proteins in sebaceous gland carcinoma. Head $\mathcal{E}$ neck.

FENG M, G YANG AND J WU 2011. Versican targeting by RNA interference suppresses aggregative growth of dermal papilla cells. Clinical and experimental dermatology. 36:77-84.

FERNANDES KJ, IA MCKENZIE, P MILL, KM SMITH, M AKHAVAN, F BARNABE-HEIDER, J BIERNASKIE, A JUNEK, NR KOBAYASHI, JG TOMA, DR KAPLAN, PA LABOSKY, V RAFUSE, CC HUI AND FD MILLER 2004. A dermal niche for multipotent adult skin-derived precursor cells. Nat Cell Biol. 6:1082-1093.

FRANCES D AND C NIEMANN 2012. Stem cell dynamics in sebaceous gland morphogenesis in mouse skin. Developmental biology. 363:138-146.

FUCHS E. 2007. Scratching the surface of skin development. Nature. 445:834-842.

FUCHS E AND H GREEN 1980. Changes in keratin gene expression during terminal differentiation of the keratinocyte. Cell. 19:1033-1042.
Fuchs, E., and S. Raghavan. 2002. Getting under the skin of epidermal morphogenesis. Nat Rev Genet. 3:199-209.

GAO J, MC DEROUEN, CH CHEN, M NGUYEN, NT NGUYEN, H.IDO, K HARADA, K SEKIGUCHI, BA MORGAN, JH MINER, AE ORO AND MP MARINKOVICH 2008. Laminin-511 is an epithelial message promoting dermal papilla development and function during early hair morphogenesis. Genes Dev. 22:2111-2124.

GASPARD N AND P VANDERHAEGHEN 2010. Mechanisms of neural specification from embryonic stem cells. Curr Opin Neurobiol. 20:37-43.

GECZY T, A OLAH, BI TOTH, G CZIFRA, AG SZOLLOSI, T SZABO, CC ZOUBOULIS, R PAUS AND T BIRO 2012. Protein kinase C isoforms have differential roles in the regulation of human sebocyte biology. I Invest Dermatol. 132:1988-1997.

HAN G, AG LI, YY LIANG, P OWENS, W HE, S LU, Y YOSHIMATSU, D WANG, P TEN DIJKE, X LIN AND XJ WANG 2006. Smad7-induced beta-catenin degradation alters epidermal appendage development. Dev Cell. 11:301-312.

HOOGDUIJN MJ, E GORJUP AND PG GENEVER 2006. Comparative characterization of hair follicle dermal stem cells and bone marrow mesenchymal stem cells. Stem cells and development. 15:49-60.

HORSLEY V, D O'CARROLL, R TOOZE, Y OHINATA, M SAITOU, T OBUKHANYCH, M NUSSENZWEIG, A TARAKHOVSKY AND E FUCHS 2006. Blimp1 defines a progenitor population that governs cellular input to the sebaceous gland. Cell. 126:597-609.

IIDA M, S IHARA AND T MATSUZAKI 2007. Follicular epithelia and dermal papillae of mouse vibrissal follicles qualitatively change their hair-forming ability during anagen. Differentiation; research in biological diversity. 75:371-381.

JAHODA CA AND AJ REYNOLDS 2001. Hair follicle dermal sheath cells: unsung participants in wound healing. Lancet. 358:1445-1448.

JENSEN KB, CA COLLINS, E NASCIMENTO, DW TAN, M FRYE, S ITAMI AND FM WATT 2009. Lrig1 expression defines a distinct multipotent stem cell population in mammalian epidermis. Cell stem cell. 4:427-439.

JONES LN, TJ HORR AND IJ KAPLIN 1994. Formation of surface membranes in developing mammalian hair fibres. Micron. 25:589-595.

KANITAKIS, J. 2002. Anatomy, histology and immunohistochemistry of normal human skin. Eur J Dermatol. 12:390-399; quiz 400-391.

KARLSSON L, C BONDJERS AND C BETSHOLTZ 1999. Roles for PDGF-A and sonic hedgehog in development of mesenchymal components of the hair follicle. Development (Cambridge, England). 126:2611-2621.

KASPER M, V JAKS, A ARE, A BERGSTROM, A SCHWAGER, J SVARD, S TEGLUND, N BARKER AND R TOFTGARD 2011. Wounding enhances epidermal tumorigenesis by recruiting hair follicle keratinocytes. Proc Natl Acad Sci U S A. 108:4099-4104.

KAUR P AND A LI 2000. Adhesive properties of human basal epidermal cells: an analysis of keratinocyte stem cells, transit amplifying cells, and postmitotic differentiating cells. J Invest Dermatol. 114:413-420.

KOLEV V, A MANDINOVA, J GUINEA-VINIEGRA, B HU, K LEFORT, C LAMBERTINI, $\mathrm{V}$ NEEL, $\mathrm{R}$ DUMMER, EF WAGNER AND GP DOTTO 2008. EGFR signalling as a negative regulator of Notch1 gene transcription and function in proliferating keratinocytes and cancer. Nat Cell Biol. 10:902-911.

KOSTER MI AND DR ROOP 2007. Mechanisms regulating epithelial stratification. Annual review of cell and developmental biology. 23:93-113.

LI, A., P.J. SIMMONS, AND P. KAUR. 1998. Identification and isolation of candidate human keratinocyte stem cells based on cell surface phenotype. Proc Natl Acad Sci U S A. 95:3902-3907.

LOBITZ WC, JR AND RL DOBSON 1961. Dermatology: the eccrine sweat glands. Annu Rev Med. 12:289-298.

LORENZ K, M SICKER, E SCHMELZER, T RUPF, J SALVETTER, M SCHULZ-SIEGMUND AND A BADER 2008. Multilineage differentiation potential of human dermal skin-derived fibroblasts. Experimental dermatology. 17:925-932

M'BONEKO V AND HJ MERKER 1988. Development and morphology of the periderm of mouse embryos (days 9-12 of gestation). Acta Anat (Basel). 133:325-336.

MECKLENBURG L, M NAKAMURA, JP SUNDBERG AND R PAUS 2001. The nude mouse skin phenotype: the role of Foxn1 in hair follicle development and cycling. Exp Mol Pathol. 71:171-178.

MICHNO K, K BORAS-GRANIC, P MILL, CC HUI, AND PA HAMEL 2003. Shh expression is required for embryonic hair follicle but not mammary gland development. Developmental biology. 264:153-165.

MII S, Y MURAKUMO, N ASAI, M JIJIWA, S HAGIWARA, T KATO, M ASAI, A ENOMOTO, K USHIDA, S SOBUE, M ICHIHARA AND M TAKAHASHI 2012. Epidermal Hyperplasia and Appendage Abnormalities in Mice Lacking CD109. The American journal of pathology. 
MIKKOLA ML 2007. Genetic basis of skin appendage development. Semin Cell Dev Biol. 18:225-236.

MILLAR SE 2002. Molecular mechanisms regulating hair follicle development. J Invest Dermatol. 118:216-225.

MILLAR SE, K WILLERT, PC SALINAS, H ROELINK, R NUSSE, DJ SUSSMAN AND GS BARSH 1999. WNT signaling in the control of hair growth and structure. Developmental biology. 207:133-149.

NAKAMURA M, JP SUNDBERG AND R PAUS 2001. Mutant laboratory mice with abnormalities in hair follicle morphogenesis, cycling, and/or structure: annotated tables. Experimental dermatology. 10:369-390.

NOWAK JA, L POLAK, HA PASOLLI AND E FUCHS 2008. Hair follicle stem cells are specified and function in early skin morphogenesis. Cell stem cell. 3:33-43.

OHYAMA M, Y ZHENG, R PAUS AND KS STENN 2010. The mesenchymal component of hair follicle neogenesis: background, methods and molecular characterization. Experimental dermatology. 19:89-99.

PAN Y, MH LIN, X TIAN, HT CHENG, T GRIDLEY, J SHEN AND R KOPAN. 2004. gamma-secretase functions through Notch signaling to maintain skin appendages but is not required for their patterning or initial morphogenesis. Dev Cell. 7:731-743.

PANTELEYEV AA, CA JAHODA AND AM CHRISTIANO 2001. Hair follicle predetermination. J Cell Sci. 114:3419-3431.

PELLEGRINI G, E DELLAMBRA, O GOLISANO, E MARTINELLI, I FANTOZZI, S BONDANZA, D PONZIN, F MCKEON AND M DE LUCA 2001. p63 identifies keratinocyte stem cells. Proc Natl Acad Sci U S A. 98:3156-3161.

PHILPOTT M AND R PAUS 1998. Principles of hair follicle morphogenesis. In: Molecular Basis of Epithelial Appendage Morphogenesis. R.G.Landes, Austin:75-110

PROST-SQUARCIONI C 2006. [Histology of skin and hair follicle]. Med Sci (Paris). 22:131-137.

PROST-SQUARCIONI C, S FRAITAG, M HELLER AND N BOEHM 2008. [Functional histology of dermis]. Annales de dermatologie et de venereologie. 135:1S5-20.

REDDY S, T ANDL, A BAGASRA, MM LU, DJ EPSTEIN, EE MORRISEY AND SE MILLAR 2001. Characterization of Wnt gene expression in developing and postnatal hair follicles and identification of Wnt5a as a target of Sonic hedgehog in hair follicle morphogenesis. Mechanisms of development. 107:69-82.

RICHERT MM, KL SCHWERTFEGER, JW RYDER AND SM ANDERSON 2000. An atlas of mouse mammary gland development. I Mammary Gland Biol Neoplasia. 5:227-241.

RINN JL, C BONDRE, HB GLADSTONE, PO BROWN AND HY CHANG 2006. Anatomic demarcation by positional variation in fibroblast gene expression programs. PLoS genetics. 2:e119.

RINN JL, JK WANG, N ALLEN, SA BRUGMANN, AJ MIKELS, H LIU, TW RIDKY, HS STADLER, R NUSSE, JA HELMS AND HY CHANG 2008. A dermal HOX transcriptional program regulates site-specific epidermal fate. Genes Dev. 22:303-307.

SCHLAKE T 2007. Determination of hair structure and shape. Semin Cell Dev Biol. 18:267-273.

SCHMIDT-ULLRICH R AND R PAUS 2005. Molecular principles of hair follicle induction and morphogenesis. Bioessays. 27:247-261.

SCHNEIDER MR AND R PAUS 2010. Sebocytes, multifaceted epithelial cells: lipid production and holocrine secretion. Int J Biochem Cell Biol. 42:181-185.

SCHNEIDER MR, R SCHMIDT-ULLRICH AND R PAUS 2009. The hair follicle as a dynamic miniorgan. Curr Biol. 19:R132-142.

SELLERI S, H SELTMANN, S GARIBOLDI, YF SHIRAI, A BALSARI, CC ZOUBOULIS AND C RUMIO 2006. Doxorubicin-induced alopecia is associated with sebaceous gland degeneration. I Invest Dermatol. 126:711-720

SERRE G, V MILS, M HAFTEK, C VINCENT, F CROUTE, A REANO, JP OUHAYOUN S BETTINGER AND JP SOLEILHAVOUP 1991.
Identification of late differentiation antigens of human cornified epithelia, expressed in re-organized desmosomes and bound to crosslinked envelope. J Invest Dermatol. 97:1061-1072.

SIMPSON CL, DM PATEL AND KJ GREEN 2011. Deconstructing the skin: cytoarchitectural determinants of epidermal morphogenesis. Nat Rev Mol Cell Bio. 12:565-580.

SNIPPERT HJ, A HAEGEBARTH, M KASPER, V JAKS, JH VAN ES, N BARKER, M VAN DE WETERING, M VAN DEN BORN, H BEGTHEL, RG VRIES, DE STANGE, R TOFTGARD AND H CLEVERS 2010. Lgr6 marks stem cells in the hair follicle that generate all cell lineages of the skin. Science. 327:1385-1389.

SORRELL JM AND AI CAPLAN 2004. Fibroblast heterogeneity: more than skin deep. J Cell Sci. 117:667-675.

STENN KS AND R PAUS 1999. What controls hair follicle cycling? Experimental dermatology. 8:229-233; discussion 233-226.

STENN KS AND R PAUS 2001. Controls of hair follicle cycling. Physiol Rev. 81:449-494.

SUZUKI Y, H MIURA, A TANEMURA, K KOBAYASHI, G KONDOH, S SANO, K OZAWA, S INUI, A NAKATA, T TAKAGI, M TOHYAMA, K YOSHIKAWA AND S ITAMI 2002. Targeted disruption of LIG-1 gene results in psoriasiform epidermal hyperplasia. FEBS Lett. 521:67-71.

TANI H, RJ MORRIS AND P KAUR 2000. Enrichment for murine keratinocyte stem cells based on cell surface phenotype. Proc Natl Acad Sci U S A. 97:10960-10965.

TOMA JG, M AKHAVAN, KJ FERNANDES, F BARNABE-HEIDER, A SADIKOT, DR KAPLAN AND FD MILLER 2001. Isolation of multipotent adult stem cells from the dermis of mammalian skin. Nat Cell Biol. 3:778-784.

TREMPUS CS, RJ MORRIS, CD BORTNER, G COTSARELIS, RS FAIRCLOTH, JM REESCE AND RW TENNANT 2003. Enrichment for living murine keratinocytes from the hair follicle bulge with the cell surface marker CD34. J Invest Dermatol. 120:501-511.

TSAI SY, C CLAVEL, S KIM, YS ANG, L GRISANTI, DF LEE, K KELLEY AND M RENDL 2010. Oct4 and klf4 reprogram dermal papilla cells into induced pluripotent stem cells. Stem cells (Dayton, Ohio). 28:221-228.

TSAI SY, BA BOUWMAN, YS ANG, SJ KIM, DF LEE, IR LEMISCHKA AND M RENDL 2011. Single transcription factor reprogramming of hair follicle dermal papilla cells to induced pluripotent stem cells. Stem cells (Dayton, Ohio). 29:964-971.

TUMBAR T, G GUASCH, V GRECO, C BLANPAIN, WE LOWRY, M RENDL AND E FUCHS 2004. Defining the epithelial stem cell niche in skin. Science. 303:359-363.

WATT FM AND KB JENSEN 2009. Epidermal stem cell diversity and quiescence. EMBO Mol Med. 1:260-267.

WILSON PA, AND A HEMMATI-BRIVANLOU 1995. Induction of epidermis and inhibition of neural fate by Bmp-4. Nature. 376:331-333.

WONG VW, B LEVI, J RAJADAS, MT LONGAKER AND GC GURTNER 2012. Stem cell niches for skin regeneration. International journal of biomaterials. 2012:926059.

WOO WM, HH ZHEN AND AE ORO 2012. Sh maintains dermal papilla identity and hair morphogenesis via a Noggin-Shh regulatory loop. Genes Dev. 26:1235-1246.

YAMAMOTO N, K TANIGAKI, H HAN, H HIAI AND T HONIO 2003. Notch/RBP-J signaling regulates epidermis/hair fate determination of hair follicular stem cells. Current biology : CB. 13:333-338.

ZHAN, Y, P TOMANN, T ANDL, NM GALLANT, J HUELSKEN, B JERCHOW, W BIRCHMEIER, R PAUS, S PICCOLO, ML MIKKOLA, EE MORRISEY, PA OVERBEEK, C SCHEIDEREIT, SE MILLAR,AND R SCHMIDT-ULLRICH 2009. Reciprocal requirements for EDA/EDAR/ NF-kappaB and Wnt/beta-catenin signaling pathways in hair follicle induction. Dev Cell. 17:49-61. 